\title{
Effectiveness of Art Therapy on Social and Communication Skills of Patients at Assiut University Hospital
}

\author{
Nadia Abd El-Ghany Abd El- Hameed, Rada Abd Elal Thabet, Ahmed Abd El-Baki Abd El-Rahman \\ Lecturer of Psychiatric and Mental Health Nursing, Faculty of Nursing, Assiut University, \\ Lecturer of Psychiatric and Mental Health Nursing, Faculty of Nursing, Assiut University, \\ Lecturer of Neurology and Psychiatry, Faculty of Medicine, Assuit University
}

\begin{abstract}
Art therapy is a form of psychotherapy. Art therapy uses the creative process of art making to improve and enhance the physical, mental and emotional well-being of patients. Art therapy program may be help to stimulate patient's interaction and communicate with others and help them be socially interaction and independent. The aim: of this study was to assess, plan, implement, and evaluate the effect of art therapy on social and communication skills among psychiatric patient at assiut university hospital. Research design: quasi-experimental design (pre- and post test) was used. The setting: this study was carried out at inpatient psychiatric unit for males and females, at Assiut University Hospital. Subject \& Method: the subjects include in the study \& control group comprised of 100 schizophrenic and mood disorder(depressive) patients who were attending to psychiatric unit within a Period of 4 months. Study tools, Three tools; were used to collect the study data (I) Sociodemographic data (2) Social Skills Assessment Scale (SSAS), \& (3) Communication skills assessment scale (CSAS). SSAS and CSAS Scales were used before and after implement of art therapy sessions .Results: revealed significant improvement in social and communication skills after application of the sessions of art therapy program especially social interaction and expression of feelings among studied group while control group no significant before and after program . Conclusion: It can be concluded that art therapy sessions are effective in improving communication and social interaction as well as social interest and cooperation. The study recommended: nurses must be implement and apply art therapy as a treatment and part of nursing care plan.
\end{abstract}

\section{Key Words: Art Therapy, Social Skills \& Communication Skills}

\section{Introduction}

Art therapy is an effective treatment for the developmentally, medically, educationally, socially, or psychologically impaired; and is practiced in mental health, rehabilitation, medical, educational, and forensic institutions. Populations of all ages, races, and ethnic backgrounds are served by art therapists in individual, couples, family and group therapy formats (Cohen\& Bruce, 2009)

Art therapy defined as a human service profession that uses art media, images, the creative process, and patient/client responses to the created products as reflections of an individual's development, abilities, personality, interests, concerns, and conflicts. Art therapy practice is based on knowledge of human developmental and psychological theories which are implemented in the full spectrum of models of assessment and treatment including educational, psychodynamic, cognitive, transpersonal, and other therapeutic means of reconciling emotional conflicts, fostering self-awareness, developing social skills, managing behavior, solving problems, reducing anxiety, aiding reality orientation, and increasing self-esteem.(American Art Therapy Association, 2010)
Art therapy has included studying the influence of depression on the content of drawings, the use of art to assess cognitive skills, the correlation of psychiatric diagnosis and formal variables in art, and the effect of art therapy interventions (http://www.nccata, 2010).

The American Art Therapy Association define "art therapy as the therapeutic use of art making, within a professional relationship, by people who experience illness, trauma or challenges in living, and by people who seek personal development. Through creating art and reflecting on the art products and processes, people can increase awareness of self and others cope with symptoms, stress and traumatic experiences; enhance cognitive abilities; and enjoy the lifeaffirming pleasures of making art [http://www.americanarttherapyassociatio3]

Art therapy is a mental health profession that uses the creative process of art making to improve and enhance the physical, mental and emotional wellbeing of individuals of all ages. It is based on the belief that the creative process involved in artistic self-expression helps people to resolve conflicts and problems, develop interpersonal skills, manage 
behavior, reduce stress, increase self-esteem and selfawareness, and achieve insight. Art therapy integrates the fields of human development, visual art (drawing, painting, sculpture, short story and other art forms), and the creative process with models of counseling and psychotherapy. (Van Lith, Fenner \& Schofield, 2012).

Art therapy program had been used in the treatment of mental person because helps bring to consciousness thought and felling that would otherwise remain unexpressed or people who cannot share their thoughts and felling adequately through the tried- and- true traditional methods of "talk therapy conversation". Art therapy program which include s painting, drawing, and music therapy as well as shorting story, has been effective shown to be an effective method to reduce symptoms of depression and schizophrenia. (Finnegan, 2009). Arts therapy program encourage self expression and promote self awareness leading to improve mental health especially reduction general symptoms of schizophrenia (Crawford\&Patterson,2007).

Communication skills is the part of social skills. The development of social skills and how to interact with others this is dependent on the early development (Abd El- hameed ,2008). Patients with social skills deficits such as problems with communication with others people, social withdrawal, problems with activities of daily living should be offered to social skills training.( Vyskocilova, \& Prasko,2012, Edwards, 2004). Patients with mental illness have lack of ability to initiate and lor maintain relationship and communication with others. Art therapy assist individual with mental illness to reduce social isolation and facilitated communication among individuals,develop insight and increase self-esteem (Mcgarry\&Prince, 1998).

Significance of the study:

Art therapy is a mental health profession that uses the creative process of art making to improve and enhance the mental and emotional well-being of individuals of all ages. Communication skills are important to overall well- being, for creating positive interpersonal atmosphere and for solving interpersonal problems. Many patients with various psychiatric disorders suffer from either a statedependent decrease of social skills or lifelong deficits of such skills. Patients with social skills deficits such as problems with communication with others people, social withdrawal, problems with activities of daily living should be offered to social skills training. So the present study trying to researched this topic.

\section{Aim of the study}

The aim of this study was to assess, plan, implement, and evaluate the effect of art therapy on social and communication skills among psychiatric patient at assiut university hospital

\section{Research Questions}

Are the social and communication skills of psychiatric patients well be improved after receiving an art therapy program than before or not?

\section{Hypothesis}

The present study hypothesized the patient will be improved social and communication skills after implement the art therapy program.

\section{Subject \& Method}

Research Design: the quasi-experimental design (pre- and post test design) was used.

\section{1- Setting:}

The study was conducted at inpatient psychiatric unit at Assiut University Hospital.

\section{2- Subjects:}

A convenient sample of the study comprised of 100 psychiatric patients classified into50 studied and 50 control group of schizophrenic and mood disorder (Depressive) patients who were attending to the psychiatric unit within a period of 5 months from August to December 2012, both gender agree to participate in the study, their aged were ranged from $13-50$ years.

\section{Inclusion criteria}

1- Patient diagnosed of schizophrenic, and patients with mood disorder (depressive) or major depressive disorders

2- They are able to interact

Study Tools

There are three tools were used in this study:-

Tool (1): Sociodemographic data sheet:-

This tool developed by the researchers, which include age, sex, level of education, marital statues, occupation, diagnosis and residence.

Tool (II) Social Skills Assessment Scale ( SSAS) It was used to assess social skills and developed by Fbian (1997) and was translated into Arabic by Elmastkawy (2004) and back translation into English was done to check validity. It consists of 17 sentences answered by "yes" when the skill is present and "no" if the skill is absent. Each sentence represents a social skill. If more than 7 sentences were answered by "yes" this indicates good social skills, and 7or less sentences indicates poor social skills. The Arabic Translation of Social Skills Assessment Scale showed validity, and reliability by using Pearson correlation one tailed method of each item with the total score of the scale was found to be high $\mathbf{r}=\mathbf{0 . 6 6}$. The validity and reliability were done by Elmastkawy. Mean \pm SD $(30.08 \pm 12.69)$ for the total score were computed (Ahmad 2005). 


\section{Tool (III) Communication Skills Assessment Scale (CSAS)}

A communication skill assessment scale developed by Western Carolina University (1997) and was translated into Arabic by Elmastkawy and back translation into English was done to check validity. It consists of 14 items. It was scored from 1 to 5, the higher the score the higher the ability to communicate. The Arabic translation of the communication skills assessment scale was found to be valid and internal consistency of each item by using Pearson correlation one tailed method of each item with the total score of the scale was found to be high $\mathbf{r}=\mathbf{0 . 8 2}$. The validity and reliability of the scale was done by Elmastkawy. Mean \pm SD (30.08 \pm 12.69) for the total score also computed (Ahmad 2005).

The Procedure

A- Assessment phase

The first step The investigator was interview the psychotic patients at the Psychiatric unit in Assuit University Hospital. All ethical considerations were clarified to each patient throw oral consent before explanation of the nature of the study. The investigator was asked the patient about their sociodemographic data by using the first questionnaire to determine the sociodemographic data for these patients.

The second step

Applied SSAS and CSAS skills (tool no 1 and tool no

2) applied for each patients to measure social and communication skills of those patients

\section{B- Implementation phase}

Then the art therapy program was applied for each patient. Implementation of art therapy sessions included: an orientation meeting was held with patients to explain the aim of the art therapy sessions, the art therapy sessions were held for 3 days / week for a period of 4 weeks, every session was for one hour, art therapy sessions included different types of activities received by every subject in the group as the following

1- Drawing

2- Painting

3- Short stories

The program was applied for psychiatric patients (schizophrenic\& Mood disorder "depressive" and Major depressive disorders in Psychiatric unit at Assuit University Hospital, each patient interviewed in a group, number of group for each session ranged from 5 to 7 patients.

\section{C- Evaluation phase}

Firstly pre- test was done for patients before application the program and then post test was immediately done, post- program implementation to evaluate the effectiveness of the program and the improvement of social and communication skills of the subject. Data were collected in the period from August to December 2012.

Method of data collection

1) Permission was obtained from the dean of the faculty of nursing -Assiut University and submits to the medical director of the Psychiatric unit at Assuit University Hospital

2) The aim of the study was explained to patients before starting data collection. Patients were informed about what will be done for them.

3) Each patient has been interviewed once in a group of 5 or 7 patient's basis at psychiatric unit.

4) The data were collected by the researchers during the period of five months from the first of August till the end of December 2012.

5) The patient was interviewed for about one hour at one time.

6) Pilot study; It was carried out on 5 patients (depressed, schizophrenia, those patients were excluded from the study sample) before starting data collection in order to test the applicability and relevance of the tools. There was no modification done based on the finding of the pilot study.

Ethical consideration, consent (verbal agreement) was taken from the patients who were reassured about the confidentiality of the obtained information to avoid misunderstanding and providing privacy for them. All ethical consideration was clarified to each one before explanation of the nature of the study.

Statistical analysis

The data were computerized and verified using the SPSS (statistic among package for social science) version 16 to perform tabulation and statistical analysis. Quantitative variables were described in frequency and percentages, statistical significance was considered at $\mathrm{p}-$ value $<0.05$. Using Wilcox on Signed Ranks Test NPr test as well as Pearson correlation test. 


\section{Results}

Table (1): Sociodemographic data of the studied \& control group (No 100)

\begin{tabular}{|c|c|c|c|c|}
\hline \multirow[t]{2}{*}{ Sociodemographic data } & \multicolumn{2}{|c|}{ Control group } & \multicolumn{2}{|c|}{ Studied group } \\
\hline & No. $(n=50)$ & $\%$ & No. $(n=50)$ & $\%$ \\
\hline \multicolumn{5}{|l|}{ Age: (years) } \\
\hline (Mean \pm SD Range & \multicolumn{2}{|c|}{$2.32 \pm 0.802$} & \multicolumn{2}{|c|}{$32.58 \pm 9.98(13-56)$} \\
\hline Teenagers & 10 & 20.0 & 4 & 8.0 \\
\hline Adults & 14 & 28.0 & 35 & 70.0 \\
\hline Middle aged & 26 & 52.0 & 3 & 22.0 \\
\hline \multicolumn{5}{|l|}{ Sex } \\
\hline Male & 36 & 72.0 & 24 & 48.0 \\
\hline Female & 14 & 28.0 & 26 & 52.0 \\
\hline \multicolumn{5}{|l|}{ Marital status } \\
\hline Single & 36 & 72.0 & 28 & 56.0 \\
\hline Married & 14 & 28.0 & 18 & 36.0 \\
\hline Divorced\& Widow & 0 & 0.0 & 4 & 8.0 \\
\hline \multicolumn{5}{|l|}{ Level of education } \\
\hline Illiterate & 20 & 40.0 & 14 & 28.0 \\
\hline Primary\& Preparatory & 12 & 24.0 & 9 & 18.0 \\
\hline Secondary & 6 & 12.0 & 22 & 44.0 \\
\hline University & 12 & 24.0 & 5 & 10.0 \\
\hline \multicolumn{5}{|l|}{ Occupation } \\
\hline Not working & 26 & 52.0 & 36 & 72.0 \\
\hline Working & 20 & 40.0 & 10 & 20.0 \\
\hline Student & 4 & 8.0 & 4 & 8.0 \\
\hline \multicolumn{5}{|l|}{ Residence } \\
\hline Urban & 20 & 40.0 & 19 & 38.0 \\
\hline Rural & 30 & 60.0 & 31 & 62.0 \\
\hline \multicolumn{5}{|l|}{ Diagnosis } \\
\hline Major depression & 14 & 28.0 & 17 & 34.0 \\
\hline Schizophrenia & 36 & 72.0 & 33 & 66.0 \\
\hline
\end{tabular}

Figure (1) Social skills before and after implementation of art therapy program of the studied and control group (no.100)

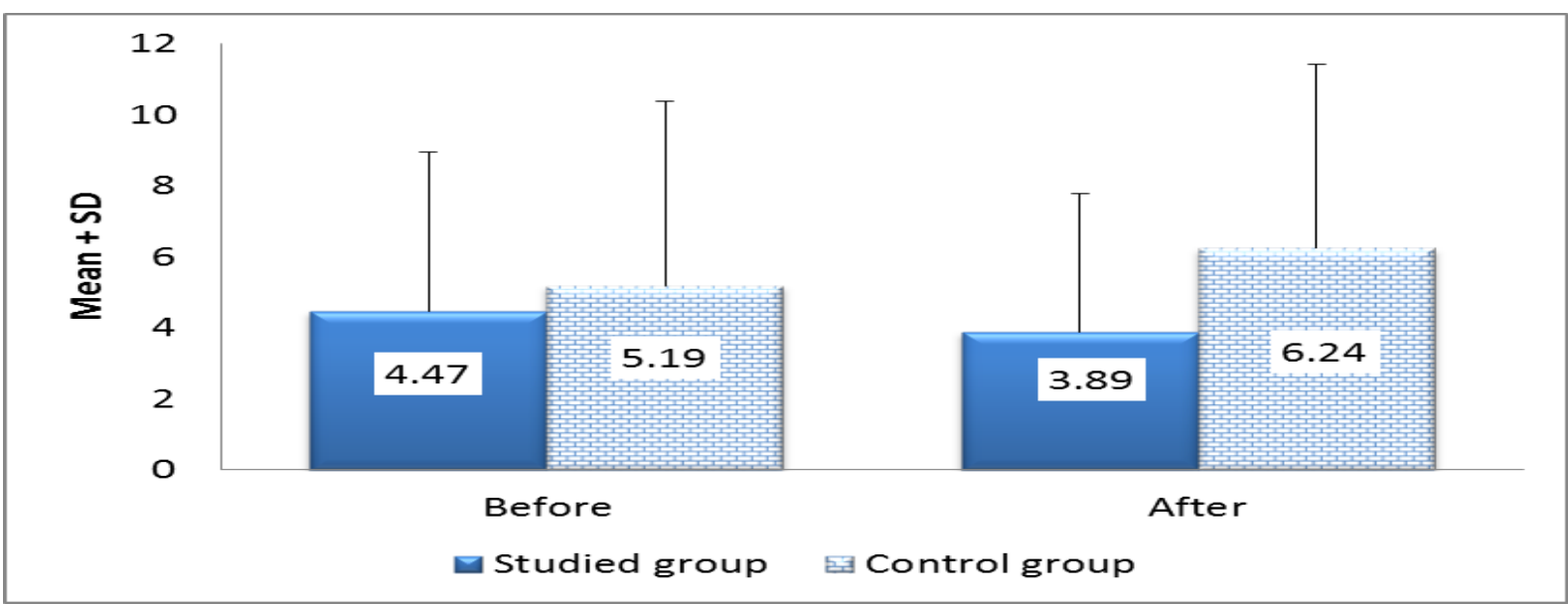

$* P$. value $=0.000$ among studied group before and after 
Figure (2) Communication skills before and after implementation of art therapy program of the studied and control group (no=100)

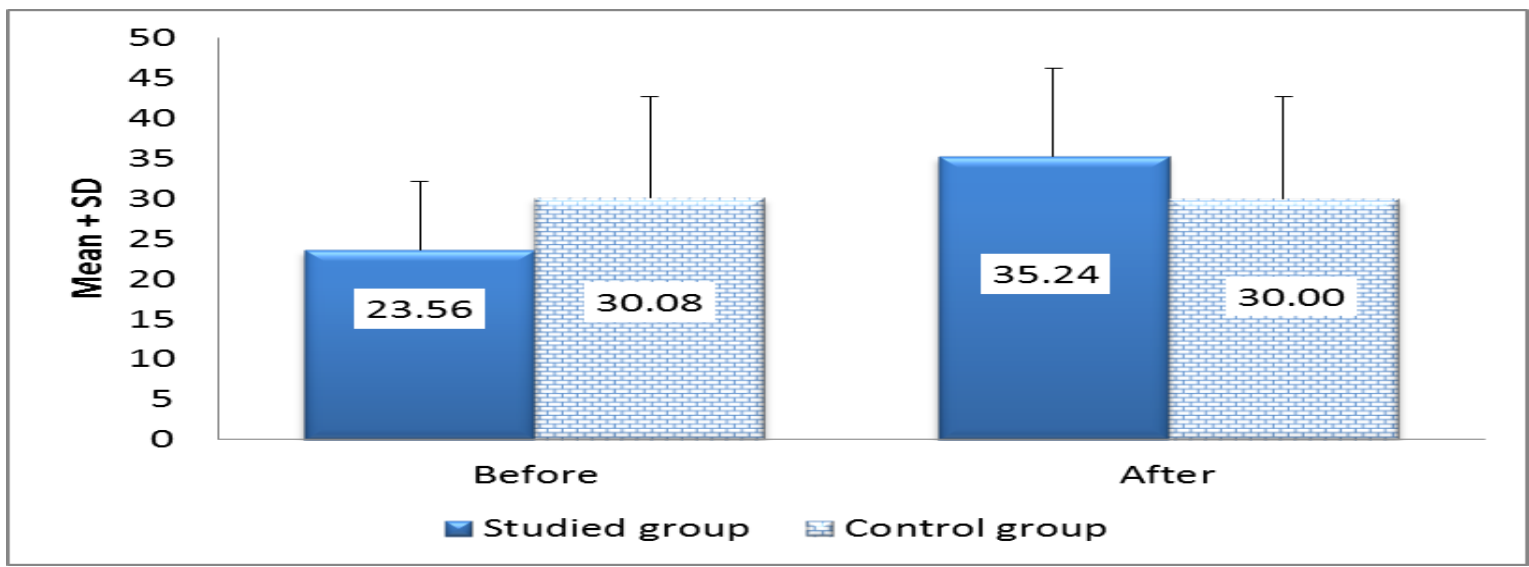

$* P$. value $=0.000$ (highly significant) among studied group before and after

Table (2): Relation between sociodemographic data and social skills of the studied \& control group (no=100)

\begin{tabular}{|c|c|c|c|c|c|c|}
\hline Sociodemographic & & & Soci & I Skills & & \\
\hline & Control grou & (50) & & Studied gro & 50) & \\
\hline Items & $\begin{array}{c}\text { Before } \\
\text { Mean } \pm \text { SD }\end{array}$ & $\begin{array}{c}\text { After } \\
\text { Mean } \pm \text { SD }\end{array}$ & P. value & $\begin{array}{c}\text { Before } \\
\text { Mean } \pm \text { SD }\end{array}$ & $\begin{array}{c}\text { After } \\
\text { Mean } \pm \text { SD }\end{array}$ & P. value \\
\hline Age: $($ years)no $=50$ & & & & & & \\
\hline Teenagers & $7 \pm 5.15$ & $7.4 \pm 5.18$ & 0.317 & $18.53 \pm 3.33$ & $28.15 \pm 7.40$ & .066 \\
\hline Adult & $4.71 \pm 5.28$ & $4.86 \pm 5.37$ & 0.564 & $24.27 \pm 9.51$ & $35.46 \pm 11.63$ & $.000 * *$ \\
\hline Middle aged & $6.62 \pm 5.41$ & $6.54 \pm 5.33$ & 0.705 & $22.57 \pm 5.59$ & $36.64 \pm 9.36$ & $.003^{*}$ \\
\hline $\begin{array}{l}\text { Sex: } \\
\text { Male }\end{array}$ & $6.61 \pm 5.18$ & $6.78 \pm 5.17$ & 0.366 & $\mathbf{\pm} 4.588 .41$ & \pm 3.5913 .08 & $0.000 * *$ \\
\hline Female & $5 \pm 5.42$ & $4.86 \pm 5.3$ & 0.564 & $7.00 \pm 4.34$ & $12.07 \pm 4.16$ & $0.000 * *$ \\
\hline Marital status: & & & & & & \\
\hline Single & $6.94 \pm 5.33$ & $7.06 \pm 5.33$ & 0.564 & $8.14 \pm 4.84$ & $12.71 \pm 3.78$ & $0.000 *$ \\
\hline Married & $4.14 \pm 4.53$ & $4.14 \pm 4.41$ & 0.999 & $7.22 \pm 4.29$ & $12.11 \pm 4.33$ & $0.000 *$ \\
\hline Divorced \&Widow & - & - & - & $6.50 \pm 251$ & $12.50 \pm 3.10$ & 0.068 \\
\hline Level of education: & & & & & & \\
\hline Illiterate $=14$ & $2.4 \pm 3.81$ & $2.4 \pm+3.72$ & 0.999 & $7.14 \pm 3.97$ & $12.28 \pm 3.14$ & $0.001 * *$ \\
\hline Primary $=3$ & $4 \pm 3.37$ & $4 \pm 3.27$ & 0.999 & $7.00 \pm 4.58$ & $14.33 \pm 2.08$ & .102 \\
\hline Preparatory $=6$ & $6 \pm 5.66$ & $7 \pm 5.66$ & 0.157 & $4.66 \pm 3.77$ & $10.83 \pm 4.30$ & $.027 *$ \\
\hline Secondary $=22$ & $13 \pm 1.73$ & $13.67 \pm 1.53$ & 0.157 & $8.40 \pm 4.58$ & $12.59 \pm 4.42$ & $.000 * *$ \\
\hline University $=5$ & $10.5 \pm 2.43$ & $10.17 \pm 2.14$ & 0.414 & $10.00 \pm 5.52$ & $14.20 \pm 3.89$ & $.043 *$ \\
\hline Residence: & & & & & & \\
\hline Urban & $9.7 \pm 4.06$ & $9.8 \pm 4.1$ & 0.739 & $8.47 \pm 4.50$ & $13.15 \pm 3.70$ & $.000 * *$ \\
\hline Rural & $3.8 \pm 4.54$ & $3.87 \pm 4.47$ & 0.655 & $7.19 \pm 4.46$ & $12.19 \pm 4.02$ & $.000 * *$ \\
\hline
\end{tabular}


Table (2) Continued

\begin{tabular}{|c|c|c|c|c|c|c|}
\hline \multirow{3}{*}{$\begin{array}{l}\text { Sociodemographic } \\
\text { data }\end{array}$} & \multicolumn{6}{|c|}{ Social Skills } \\
\hline & \multicolumn{3}{|c|}{ Control group $(50)$} & \multicolumn{3}{|c|}{ Studied group $(50)$} \\
\hline & $\begin{array}{c}\text { Before } \\
\text { Mean } \pm \text { SD }\end{array}$ & $\begin{array}{c}\text { After } \\
\text { Mean } \pm \text { SD }\end{array}$ & P. value & $\begin{array}{c}\text { Before } \\
\text { Mean } \pm \text { SD }\end{array}$ & $\begin{array}{c}\text { After } \\
\text { Mean } \pm \text { SD }\end{array}$ & P. value \\
\hline Not worked $=36$ & $4.31 \pm 4.77$ & $4.15 \pm 4.54$ & 0.414 & $7.94 \pm 4.42$ & $12.63 \pm 3.98$ & $.004 *$ \\
\hline Worked $=10$ & $8 \pm 5.48$ & $8.2 \pm 5.41$ & 0.414 & $5.80 \pm 4.10$ & $11.30 \pm 3.83$ & $.000 * *$ \\
\hline Student $=4$ & $9 \pm 2.83$ & $10 \pm 2.83$ & 0.157 & $10.00 \pm 5.35$ & $15.00 \pm 2.30$ & $.068 *$ \\
\hline \multicolumn{7}{|l|}{ Diagnosis: } \\
\hline Major depression & $6.25 \pm 5.68$ & $6.5 \pm 5.45$ & 0.564 & $3.94 \pm 2.70$ & $9.82 \pm 3.95$ & $.000 * *$ \\
\hline Schizophrenia & $6.39 \pm 5.29$ & $6.5 \pm 5.36$ & 0.527 & $9.60 \pm 3.96$ & $13.96 \pm 3.06$ & $.000 * *$ \\
\hline
\end{tabular}

Wilcoxon Signed Ranks Test * Significant ** Highly significant

Table (3): Relation between sociodemographic data and communication skills of the studied and control group $($ no $=100)$

\begin{tabular}{|c|c|c|c|c|c|c|}
\hline \multirow{3}{*}{$\begin{array}{l}\begin{array}{c}\text { Sociodemographic } \\
\text { data }\end{array} \\
\text { Items } \\
\text { Age: (years)no }=50\end{array}$} & \multicolumn{6}{|c|}{ Communication Skills } \\
\hline & \multicolumn{3}{|c|}{ Control group $(50)$} & \multicolumn{3}{|c|}{ Studied group $(50)$} \\
\hline & $\begin{array}{c}\text { Before } \\
\text { Mean } \pm \text { SD }\end{array}$ & $\begin{array}{c}\text { After } \\
\text { Mean } \pm \text { SD }\end{array}$ & P. value & $\begin{array}{c}\text { Before } \\
\text { Mean } \pm \text { SD }\end{array}$ & $\begin{array}{c}\text { After } \\
\text { Mean } \pm \text { SD }\end{array}$ & $P$. value \\
\hline Teenagers & $31.8 \pm 14.58$ & $31.2 \pm 15.66$ & 0.257 & $18.75 \pm 3.40$ & $28.25 \pm 7.50$ & .066 \\
\hline Adult & $25.29 \pm 14.61$ & $25.43 \pm 15.02$ & 0.739 & $24.37 \pm 9.51$ & $35.57 \pm 11.73$ & $.000 * *$ \\
\hline Middle aged & $32 \pm 11.23$ & $32 \pm 10.41$ & 0.999 & $22.72 \pm 5.79$ & $36.72 \pm 9.43$ & $.003^{*}$ \\
\hline \multicolumn{7}{|l|}{ Sex: } \\
\hline Male & $29.72 \pm 11.87$ & $29.78 \pm 11.69$ & 0.858 & $24.37 \pm 9.07$ & $36.79 \pm 11.65$ & $.000 * *$ \\
\hline Female & $31 \pm 15.63$ & $30.57 \pm 15.87$ & 0.334 & $22.80 \pm 8.12$ & $33.80 \pm 10.44$ & $.000 * *$ \\
\hline \multicolumn{6}{|l|}{ Marital status: } & \multirow[b]{2}{*}{$.000 * *$} \\
\hline Single & $30.44 \pm 12.6$ & $30.39 \pm 12.6$ & 0.771 & $25.17 \pm 9.98$ & $\begin{array}{l}36.53 \\
\pm 12.45\end{array}$ & \\
\hline Married & $29.14 \pm 13.91$ & $29 \pm 13.74$ & 0.792 & $22.00 \pm 6.24$ & $33.77 \pm 9.37$ & $.000 * *$ \\
\hline Divorced \&Widow & - & - & - & $19.25 \pm 3.20$ & $32.75 \pm 7.41$ & .068 \\
\hline \multicolumn{7}{|l|}{ Level of education: } \\
\hline Illiterate $=14$ & $24.3 \pm 12.32$ & $24.6 \pm 12.08$ & 0.454 & $21.71 \pm 5.59$ & $33.71 \pm 8.83$ & $.001 * *$ \\
\hline Primary $=3$ & $29.25 \pm 11.79$ & $28.25 \pm 12.5$ & 0.102 & $23.00 \pm 8.66$ & $40.33 \pm 14.46$ & .109 \\
\hline Preparatory $=6$ & $22.5 \pm 3.54$ & $23 \pm 1.41$ & 0.655 & $17.33 \pm 2.80$ & $26.83 \pm 6.55$ & $.027^{*}$ \\
\hline Secondary=22 & $44 \pm 8.19$ & $43.67 \pm 8.74$ & 0.317 & $25.86 \pm 9.44$ & $37.00 \pm 11.10$ & $.000 * *$ \\
\hline University $=5$ & $35.83 \pm 11.91$ & $35.67 \pm 12.24$ & 0.679 & $26.25 \pm 12.91$ & $38.25 \pm 3.20$ & $.043^{*}$ \\
\hline \multicolumn{7}{|l|}{ Residence: } \\
\hline Urban & $38 \pm 11.85$ & $37.9 \pm 11.85$ & 0.748 & $24.40 \pm 8.64$ & $36.80 \pm 16.25$ & $.000 * *$ \\
\hline Rural & $24.8 \pm 10.56$ & $24.73 \pm 10.48$ & 0.816 & $23.09 \pm 8.58$ & $34.32 \pm 10.83$ & $.000 * *$ \\
\hline \multicolumn{7}{|l|}{ Occupation: } \\
\hline Not worked $=36$ & $28.92 \pm+14.34$ & $29.23 \pm 14.42$ & 0.429 & $24.25 \pm 9.23$ & $35.83 \pm 11.02$ & $.005^{*}$ \\
\hline Worked $=10$ & $30.6 \pm 11.01$ & $30.2 \pm 10.63$ & 0.305 & $20.70 \pm 5.51$ & $32.80 \pm 11.13$ & $.000 * *$ \\
\hline Student $=4$ & $35 \pm 15.56$ & $34 \pm 16.97$ & 0.317 & $24.50 \pm 8.42$ & $36.00 \pm 13.08$ & .068 \\
\hline
\end{tabular}


Table (3) Continued

\begin{tabular}{|l|c|c|c|c|c|c|}
\hline Sociodemographic data & \multicolumn{3}{|c|}{ Communication Skills } \\
\hline Items & \multicolumn{3}{|c|}{ Control group(50) } & \multicolumn{3}{c|}{ Studied group(50) } \\
\hline Diagnosis:- & $\begin{array}{c}\text { Before } \\
\text { Mean } \pm \text { SD }\end{array}$ & $\begin{array}{c}\text { After } \\
\text { Mean } \pm \text { SD }\end{array}$ & P. value & $\begin{array}{c}\text { Before } \\
\text { Mean } \pm \text { SD }\end{array}$ & $\begin{array}{c}\text { After } \\
\text { Mean } \pm \text { SD }\end{array}$ & P. value \\
\hline Major depression & $22.5 \pm 6.76$ & $22 \pm 7.53$ & 0.317 & $17.11 \pm 1.86$ & $26.17 \pm 8.74$ & $.000^{* *}$ \\
\hline Schizophrenia & $30.28 \pm 13.09$ & $30.22 \pm 12.95$ & 0.771 & $26.86 \pm 8.74$ & $39.90 \pm 10.38$ & $.000^{* *}$ \\
\hline
\end{tabular}

Wilcoxon Signed Ranks Test * Significant ** Highly significant

Table (4) Correlation between social skills \& communication skills among the studied and control group (n=100)

\begin{tabular}{|c|c|c|c|c|}
\hline \multirow{2}{*}{\multicolumn{5}{|c|}{$\begin{array}{l}\text { Variables } \\
\text { Communication Skills } \\
\end{array}$}} \\
\hline & & & & \\
\hline \multirow{3}{*}{ Studied group $(50)$} & \multicolumn{2}{|c|}{ Before $(n=50)$} & \multicolumn{2}{|c|}{ After $(n=50)$} \\
\hline & $\mathbf{R}$ & $\mathbf{P}$ & $\mathbf{R}$ & $\mathbf{P}$ \\
\hline & 0.888 & $.000 * *$ & .824 & $.000 * *$ \\
\hline Control group $(50)$ & 0.738 & $0.000 * *$ & 0.697 & $0.000 * *$ \\
\hline
\end{tabular}

$* * P<0.001$ highly significant

In the table (1) it was, found that, the mean age of the study group, was $33.45 \pm 8.51$ (13- 56 years)while control group 2.32 $\pm 0.802(15-60)$. Most of the studied group was in adult aged while control group was in middle aged . As regarding to gender, number of females were more than males $(52 \%, 48 \%$ ) while control group the number of males were more than females $(72.0 \%, 0.28 \%)$.

Regarding to marital status $56 \%$ (28) of the studied group were single and $36 \%$ (18) were married, while small number of them were divorced \& widowed (8\%) While control group72\% (36) of the studied group were single and $28 \%$ (14) were married.,

According to the level of education, the majority of studied group were secondary level of education, (44\%) while control group the majority of them were illiterate $40 \%$.As regard occupation about $52 \%$ of the studied group were not working, While $20 \%$ of them were working and $8 \%$ were students. while control group $72 \%$ of them were not working, While $40 \%$ of them were working and $8 \%$ were students. More than half $(62 \%)$ of the studied group and control group were living in rural area, the majority of studied group were schizophrenia $(66 \%)$ control group $(72 \%)$, and major depression was $(34 \%, 28 \%)$ respectively .

Figure (1) illustrated those improved social skills after implementation of the art therapy program among the studied group. Highly statistically significant difference of social skills before and after implementation of the art therapy program was found that $\mathrm{p}$ value $=(0.001)$. With the mean scores equal 7.68 to 12.56 immediately after the program. According to control group there was no statistically significant difference of social skills before and after implementation of the art therapy program was found that $\mathrm{P}$ value was( 0.696) With the mean scores = $6.16,6.24$.

Figure (2) illustrated those improved communication skills after implementation of the art therapy program among the studied group. Highly statistically significant difference of communication skills before and after implementation of the art therapy program was found which $\mathbf{p}$ value $=(0.000)$ with the mean scores equal 23.56, 35.24 immediately after the program. Regarding control group no statistically significant difference of communication skills before and after implementation of the art therapy program was found which $\mathbf{p}$ value was $(\mathbf{0 . 5 9 3})$. With the mean scores equal 30.08, 30.00 immediately after the program.

Table (2): showed the relation between sociodemographic data and social skills among the studied group. There were highly statistically significant difference between adult and middle aged group\& social skills $(\mathrm{p}=0.000 ; 0.003)$ respectively, while control group there were no statistically significant difference between adult and middle aged group\& social skills $(0.317,0.564,0.705)$ Regarding gender ; there were highly statistically significant difference between social skills and gender $(p=0.000)$ while control group there were no statistically significant difference between social skills and gender $p=(0.366,0.564)$. According to marital status; highly statistically significant difference was found between social skills \&single and married patient $(\mathrm{p}=0.000)$. Control group there was no statistical significant difference was found between social skills \&single and married patient ( $p>0.05)$. As regarding level of education the present study reported that, there were highly statistically significant differences between social skills and secondary level of education \& with illiterate patients 
at $(\mathrm{p}$ value $=0.000,0.001)$. While control group there were no statistically significant differences between social skills and level of education ( $\mathrm{p}$ value $>0.05$ ). The present study reported that highly statistically significant difference was found between social skills and residence (urban and rural) $\mathrm{p}$ value $=0.000$ respectively. Was no statistical significant difference between social skills and residence regarding control group. According to occupation; there were highly statistically significant differences between social skills and occupation (not work and work) $\mathrm{p}=0.004$; 0.000 respectively, while control group no statistical significant difference between social skills and occupation. According to diagnosis; there were highly statistically significant difference between social skills and diagnosis (major depression \& schizophrenia) $\mathrm{p}=(0.000)$. Control group was no statistically significant difference between social skills and diagnosis $(\mathrm{P}>0.05)$.

Table (3) : showed the relation between sociodemographic data and communication skills among the studied group. There were highly statistically significant differences between adult and middle aged group\& communication skills $(\mathrm{p}=$ $0.000 ; 0.003)$ respectively. According to control group were no statistically significant differences between aged group\& communication skills. There were highly statistically significant difference between communication skills and gender ( $\mathrm{p}=$ 0.000). As regard control group were no statistically significant difference between communication skills and gender. According to marital status; highly statistically significant differences between communication skills \&single and married patient $(\mathrm{p}=0.000)$. According to control group no statistically significant difference between communication skills \& married statues The present study reported that statistically significant differences between communication skills with different levels of education at $\mathrm{p}$ value (.000) while control group was no statistically significant difference between levels of education and communication skills .Also there was a highly statistically significant differences between communication skills and residence (urban and rural) $\mathrm{p}$ value $=(0.000)$. While control group was no statistically significant differences between residence and communication skills . Regarding to occupation; there were highly statistically significant differences between communication skills and occupation (not work and work) $\mathrm{p}=(0.005$; 0.000). As regard control group were no statistically significant difference between communication skills and occupation. There were highly statistically significant difference between communication skills and diagnosis (major depression \& schizophrenia) $\mathrm{p}=$ (0.000). Control group was no statistically significant differences between communication skills and diagnosis $(\mathrm{P}>0.05)$

Table (4) : It is obvious that there was a significant positive correlation between social skills and communication skills before and after implementation of the program related to studied group and control group $(\mathrm{r}=.889$, at $\mathrm{p}=.000, \mathrm{r}=.824$, at $\mathrm{p}=$ $.000)$

$\left(\mathrm{r}=0.738\right.$, at $\mathrm{p}=0.000^{* *}, \mathrm{r}=0.697$, at $\left.\mathrm{p}=0.000^{*}\right)$ respective

\section{Discussion}

Art therapy provides an opportunity for patient to socialized and interact with others. As well as facilitate the creation of new ways of coping and helped a patient cope more effectively with the distress of hearing voices ( keltner etal, 2011). Social skills have been defined as the ability to express feeling or to communicate interests and desires to others (Tsang \& Lak, 2013) .

Table no (1) : The present study found that, the mean age of the study group was $(33.45 \pm 8.51)$ more than half of studied group were females and more than half of them were single. The majority of the studied group was secondary level of education and nearly $3 / 4$ of studied group was not work may be referred to the majority of the studied group were females as well as in rural area. More than half of the studied group was living in rural area \& majority of them were schizophrenia. These result supported by (Ahmed, 2005) study who found that the majority of the studied sample was living in rural area with low level of education. The majority of the study sample were females, the highly percentage of patients were not work.

Figure no (1) : The results of the present study proved that Egyptian schizophrenia (33) and depressive disorder patients (17) showed that significant improvement in the mean score of patient social skills with others as a result of art therapy program .This finding was supported by another researches who found that chronic schizophrenic patients could improve through used of treatment regimen and social therapies such as recreational ,occupational, group activity and re socialization activities (Fortinash \& Holoday, 2000). On the same line many studies indicated this finding and reported the success of art therapy program in improving socialization, enhancing quality of treatment for the client by increasing expression and facilitating insight (Tate \& longo, 2002) . Moreover, Chinese study among 86 in patients in mental health unit reported improvement of social functioning in people with schizophrenia, who were allocated to group art therapy (Crawford\&Patterson,2007)).

Parr (2005) ,focused on how art-based community groups play an important role in developing social 
relationships and identity beyond that of stigmatized labels. The art group was valued as an important 'stepping stone' for reintegrating into wider social relationships.

The present study also reported significant improvement in the mean score of patients communication skills with others after implementation of art therapy program figure no (2). This may be due to reduction of competition when one's work, increases opportunity for expression of both negative and positive feelings, and group acceptance of self in a non competitive creative activity (Mcgarry and Prince,1998). This result is supported by another study after implementation of group activity session had more tendency to share in social interaction, starting point of conversation, talking about social topics such as their family sharing games \&joke with others (Hussien, Abd El dayem, and Ossman, 2005)

(Table $2 \& 3$ ), the result of the present study found that statistically significant differences between the majority of the sociodemographic data and social \& communication skills ( $\mathrm{P}$ value $<0.05$ ). This result not supported by Ahmed (2005) who found that no statistically significant differences between the majority of the sociodemographic characteristics(gender, marital statues, level of education , residence, and occupation ) and social \& communication skills of depressed patients. The present study showed a highly positive relationship in the mean score of frequency between social and communication skills and diagnosis (schizophrenic patients and depressive disorder patients) this refers to impaired social skills is a hallmark of schizophrenia. Social isolation and withdrawal they are consider as characteristic markers of the negative symptom .Tate \& longo (2002) reported that mood has an impact on art and conversely, the art product is capable of having an impact on mood. As well as severely depressed patient may be able to replace the spoken word with graphic symbols or drawing. Tsang \& Lak (2013) reported that strongly correlation between social skills performance and patient with schizophrenia. In addition, many researches findings reported that many people with depression exhibit deficit in social skills and social skills training has been found to be efficacious for depression. According to Vyskocilova, \& Prasko (2012) schizophrenic patients showed inability to deal effectively with social network and unable to establish and \or maintain relationships with others as well as have disturbance in their communication pattern (Hussien, Abd El dayem and Ossman, 2005) Ahmed (2005) reported that depressive disorder affects all cognitive and behavioral aspects, social and communication skills. In art therapy can help people with schizophrenia better understanding and explore their thoughts and feeling in a non confrontational way and improve negative symptoms ; increase self -esteem ; reducing social and emotional withdrawal (Garippo, 2014).

Table (4) the present study found that a highly significant differences between social skills and communication skills before and after application of the $\operatorname{program}(\mathrm{r}=0.889$ at $\mathrm{p}=0.000, \mathrm{R}=0.824$ at $\mathrm{P}=$ 0.000) respectively. Ahmed (2005) found that there was significant relation between social and communication skills among depressive patients. Bellini,(2003) reported that poor communication between individual refers to poor or lack of necessary skills and can lead to feeling of dissatisfied with others and increase anxiety and depression. Effective communication improve client understanding, trust increase satisfaction improve education \&educational health as well as increase rate of self-confidence and awareness. (Heinssen et al., 2000) found that, a common focus of social skills training program is a communication skills; which help to improve people's skills in this area might include helping them with nonverbal and assertive conversation skills that are needed in different specific situations such as beginning, holding and ending conversation or expression of feeling in appropriate ways. However, art therapy program has been facilitate the creation of new way of coping and helped a patient cope more effectively with distress and increase socialization\& improve communication.

\section{Conclusions}

based of the previous findings, statistically significant differences between social skills and communication skills before and after implementation of the program. Also there were statistically significant differences between sociodemographic data and communication \&social skills. There were highly statistically significant difference between communication skills, social skills and diagnosis (major depression \& schizophrenia). Generally there was no statistical significant difference between control group, social skills and communication skills before and after program.

\section{Recommendations}

1- Further studies must be done to determine the effect of art therapy on other psychiatric disorders and more intervention is needed to improve social and communication skills.

2- Applying art therapy to enhance creative abilities through imagination play and facilitates problem solving. 
3- Nurses must implement and apply art therapy as a treatment and part of nursing care plan.

5- Ward routine and rules should be done to facilitate use of art therapy as a treatment activity.

\section{References}

1. Abd El- Hameed, N., (2008): The effect of social skills training program on the psychosocial profile of homeless children ; Doctoral Thesis in Psychiatric \& Mental Health Nursing; Faculty of Nursing; Assuit University; pp 30 -33.

2. Ahmad, Z., (2005): Assessment of social \& communication skills of depressed patients. Master Thesis in Psychiatric \& Mental Health Nursing; Faculty of Nursing; Assuit University; pp $27-31$.

3. American Art Therapy Association (2010), Creative Art Therapies Week March 2128-2010.

4. Bellinin; (2003): Making (\& keeping) friends: A model for social skills interaction. The Report; 8(3) 1:10.

5. Crawford, M., and Patterson S., (2007): Art therapies for people with schizophrenia an emerging evidence base ; EBMH online ; vol(10); Agust; p; 68-70 .

6. Cohen, Bruce (October 2009): "Art Therapy". Literary Review: an international journal of contemporary writing 53: 32 .

7. Edwards, D., (2004): Art therapy. London, England: SAGE Publications, Ltd., p., In http://www.artlyst.com/articles/kate-middletonchampions-art-therapy.

8. El- Mistkawy, T., (2004): Arabic version of communication \& social skills assessment scale reliability and validity, In Ahmad Z.,(2005): Assessment of social and communication skills of depressed patients. Master Thesis in Psychiatric \& Mental Health Nursing; Faculty of Nursing; Assuit University; pp 27 -31.

9. Fbian, S., (1997): social skills assessment scale, communication skills assessment scale ; tt/www.socialskillsassessurcy.fab.com .In Ahmad Z., (2005): Assessment of social \& communication skills of depressed patients. Master Thesis in Psychiatric \& Mental Health Nursing; Faculty of Nursing; Assuit University; pp 27 -31 .

10. Finnegan J., (2009): The Effect of Art Therapy on Depression. Master Thesis in Adlerian Counseling \& Psychotherapy \& Art Therapy: Faculty of The Adler Graduate School; Page 419.

11. Fortnash K., \& Holoday Worret (2000): Psychiatric Mental Health Nursing ; $2^{\text {nd }}$ ed ; st Louis ,Mosby comp. ; 566-79.
12. Garippo G., (2014): Art Therapy for Schizophrenia; Medical review, Advertisement .

13. Heinssen, Robert K., Robert P., Liberman, \& Alex Kopelowicz. (2000): Psychosocial Skills Training for Schizophrenia: Lessons From the Laboratory. Schizophrenia Bulletin; 26 (1) : 21-46.

14. http://www.nccata.org/CATs_week.htm March 21-28, 2010 American Art therapy 2010 http://www.americanarttherapyassociation.org/aata-ab

15. Hussien, E., \& Abd EL Dayem S., \& Ossman L., (2005): The Effect of group Activity on schizophrenic patients interaction with others ; Alex. Scientific Nursing Journal ; vol(4) No (1) p; 25-37.

16. Keltner, N., Bostrom C., McGuiness sTm (2011): Psychiatric nursing, Chapter 23 (Introduction to Milieu management $6^{\text {th }} \mathrm{ed}$, Mosby comp ;p223

17. Mcgarry, T., Prince M., (1998): Implementation of group for creative Expression on a psychiatric Inpatient unite ; Journal of psychosocial nursing, vol(36) No(3) ;P19-24.

18. Parr, H., (2005): The arts \& mental Health: Creativity \& inclusion. Dundee: University of Dundee.

19. Tate F., \& Longo D., (2002): Art therapy Enhancing psychosocial nursing ; Journal of Psychosocial nursing vol(4); No (3) p; 41-47.

20. Tsang H., \& Lak D., (2013): Social skills ,In :JH stone M., Blouin,editors .International Encyclopedia of Rehabilitation . Available online:

21. http;//Cirrie.buffalo .edu/encyclopedia/article/45/

22. Van Lith T., Fenner P., \& Schofield M., (2012): Art Therapy in Rehabilitation. In: JH Stone, M., Blouin, editors. International Encyclopedia of Rehabilitation. Availableonline:http:/cirrie.buffalo.edu/encyclo pedia/en/article/131/outarttherapy.html

23. Vyskocilova J., \&, Prasko J., (2012): Social skills training in psychiatry; Submitted: 2012-1202 Accepted: 2012-12-17 Published online: 2013-0111- Act Nerv Super Rediviva 2012; 54(4): 159-170 ANSR540412A03 @ 2012 Act Nerv Super Rediviva

24. Western Carolina University : Communication Skills Assessment Form (1997); in File://A:ICommunication Skills Assessment Survey.htm.24-07-2003. 